\title{
CÍRCULOS DE CULTURA: HISTÓRIA DE UMA PRÁTICA DE EDUCAÇÃO POPULAR (DÉC. DE 1950 - 1960)
}

\author{
CULTURE CIRCLES: HISTORY OF A POPULAR EDUCATION PRACTICE \\ CÍRCULOS DE CULTURA: HISTORIA DE UNA PRÁCTICA DE EDUCACIÓN POPULAR
}

\author{
DALSOTTO, Mariana Parise Brandalise ${ }^{1}$ \\ LUCHESE, Terciane Ângela 2
}

\begin{abstract}
RESUMO
O artigo aborda a proposta de educação popular organizada por Paulo Freire no Brasil no início da década de 1960, enfatizando sua historicidade e sua metodologia. Inicialmente explicitamos aspectos da educação no século XX, com ênfase à década de 1950 e início de 1960, indicando a emergência da educação popular. Em seguida, a proposta de prática educacional de Paulo Freire e sua concepção de educação são pensadas a partir das práticas com as quais o educador se envolvia e da realidade histórica e geográfica na qual estava inserido. Por meio da análise documental da imprensa, apresentamos os tensionamentos e disputas em torno da educação na época, entendidas como luta de representações.
\end{abstract}

Palavras-chave: Educação popular. Círculos de Cultura. História da Educação. Paulo Freire.

\section{ABSTRACT}

The article approaches the proposal of popular education organized by Paulo Freire in Brazil in the early 1960s, explaining its historicity and methodology. Initially we explain aspects of education in the twentieth century, with emphasis on the 1950s and early 1960s, indicating the emergence of popular education. Next, Paulo Freire's educational practice proposal and its conception of education are thought from the practices with which the educator was involved and from the historical and geographical reality in which he was inserted. Finally, through documentary analysis of the press, we present the tensions and disputes around education at the time, understood as struggles of representations.

Keywords: Popular education. Culture Circles. History of Education. Paulo Freire.

\section{RESUMEN}

El artículo aborda la propuesta de educación popular organizada por Paulo Freire en Brasil a principios de la década de 1960, explicitando su historicidad y su metodología. Inicialmente explicitamos aspectos de la educación en el siglo XX, con énfasis en la década de 1950 y principios de 1960, indicando la emergencia de la educación popular. A continuación, la propuesta de práctica educativa de Paulo Freire y su concepción de educación son pensadas a partir de las prácticas en que el educador se involucra y de la realidad histórica y geográfica donde el estaba inserto. Por último, a través del análisis documental de la prensa presentamos los tensos y disputas en torno a la educación en la época, entendidas como una lucha de representaciones.

Palabras clave: Educación popular. Círculos de Cultura. Historia de la Educación. Paulo Freire.

\footnotetext{
1 Universidade de Caxias do Sul - UCS - Rio Grande do Sul - Brasil

2 Universidade de Caxias do Sul - UCS - Rio Grande do Sul - Brasil
} 
"Oficialmente inaugurada no día 7 de setembro - data máxima de nossa nacionalidade - a Fundação de Combate ao Analfabetismo que já iniciou suas patrióticas atividades, com o auxílio de 20 monitores treinados no método ultra-rápido do Dr. Paulo Freire - Alfabetização na $40^{a}$ Hora". (Jornal Diário de Pernambuco, 10 de setembro de 1963, p. 07).

"Assim, o fato de o governo federal estimular a provocação e a subversão no interior do país é uma das grandes evidências da atual conjuntura. Subitamente milhares de lavradores sem terras e sem letras estão sendo providos [...] o método Paulo Freire de alfabetização dá-Ihes as letras mas únicamente as que êles precisam para tornar-se um poderoso exército de mais de 7 milhões de eleitores [...]." (Jornal Tribuna da Imprensa, RJ, 13 de fevereiro de 1964, capa).

\section{CONSIDERAÇÕES INICIAIS}

Não é possível abordar a memória da educação popular no Brasil, sem mencionar os movimentos que surgiram no final dos anos 1950 e início de 1960. Especialmente naquele período, a educação tornou-se uma reivindicação popular, fazendo com que sua concepção, sua oferta e seus objetivos fossem reformulados de acordo com a realidade vivenciada. As duas epígrafes que introduzem o artigo são um convite à reflexão sobre a 'luta de representações', como afirma Chartier (2009), sobre como a proposta de educação e, claro, o 'Método Paulo Freire' foi representado na imprensa. Se no Diário de Pernambuco a representação é que alfabetizar pelo método configura ação patriótica, na Tribuna da Imprensa, poucos meses depois, no Rio de Janeiro, tal ato representava a uma ação de provocação, de subversão, em que um 'poderoso exército' de eleitores estava sendo preparado. Tendo como foco o movimento educacional promovido, especialmente, por Paulo Freire, buscamos apresentar, neste texto, uma breve contextualização histórica da realização dos círculos de cultura $^{3}$, entendidos como uma prática de educação popular que mobilizou a sociedade naquele período histórico.

Para isso, além do referencial bibliográfico, nos servimos da análise documental histórica da imprensa de época sob a perspectiva teórica da História da Educação e História Cultural. Primeiramente, entendemos como necessário explicitar alguns pontos sobre como a educação foi pensada no século XX, com ênfase nos anos 1950 e início de 1960. Na sequência, abordamos a emergência da educação popular e a proposta educacional formulada por Paulo Freire (a partir de suas vivências, reflexões e trocas com outras pessoas), explicitando sua metodologia. Por fim, apresentamos a concepção de educação formulada a partir da realidade do contexto no qual o educador estava inserido: o Brasil dos anos 1950 e 1960 e suas diferentes representações veiculadas pela imprensa.

\section{EDUCAÇÃO POPULAR NO BRASIL EM MEADOS DO SÉCULO XX}

A educação popular, no Brasil, nasceu a partir de uma necessidade do povo perante a realidade na qual estava vivendo e a partir de influências do pensamento que emergia na América Latina como um todo, da busca pela libertação do colonialismo e da opressão que marcavam as relações que aqui

\footnotetext{
${ }^{3}$ Como os círculos de cultura, inicialmente, foram pensados para a educação de jovens e adultos, certa ênfase a esta é dada ao longo do texto. A conceituação dos círculos de cultura é abordada a partir de Freire (1993; 2000a; 2015), Brandão (1991) e Beisiegel (1982), em subtítulo específico.
} 
se estabeleciam. Beisiegel (1982) explica que desde 1959, especialmente, várias mobilizações sociais em prol de reivindicações populares (pela liberdade e participação popular, contra a pobreza e a falta de acesso à educação, entre outros fatores) vinham acontecendo, de forma geral, na América Latina. Isto, porém, foi resultado de um histórico de movimentos anteriores e das necessidades daquele contexto. Como escreveu Paulo Rosas (2003, p. L), "os fatos mais importantes ocorreram nos anos 60. Entretanto, dificilmente teriam acontecido sem seus antecedentes imediatos, germinados sobretudo no decênio anterior, período de preparação ou amadurecimento de novas ideias [...]".

Antes ainda do período citado pelo autor, já no final do século XIX, havia a promoção da educação como fator que possibilitaria o progresso e o crescimento da sociedade tal como se pretendia para o futuro do Brasil. Desde o início do século XX houveram alguns movimentos pela reforma do sistema educativo, e a educação era entendida "[...] como um instrumento de promoção do tipo de sociedade que se pretende realizar no país". (BEISIEGEL, 1974, p. 34).

Em alguns momentos, desvinculava-se o ensino da reflexão sobre a realidade social, preocupando-se com seus aspectos técnicos. Em outros, tomava-se os aspectos políticos da educação, entendendo-a como meio para a transformação social. Houve períodos em que a preocupação com a educação perpassava suas questões quantitativas (especialmente de oferta) e períodos em que a preocupação era com a sua qualidade. Segundo Paiva (1987) e Beisiegel (1974), efetivas ações ocorreram apenas por volta da metade do século XX.

Freitas e Biccas (2009, p. 46) explicam que até a década de 1920 "[...] direitos fundamentais relacionados ao acesso à educação primária não estavam consolidados juridicamente e não havia o que pudesse garantir a expansão, a obrigatoriedade e a gratuidade do ensino público". Mesmo assim, a falta de escolarização já era tomada como um problema nacional, o que contribuiu para que a educação deixasse de ser entendida como um privilégio das classes dominantes e, nas décadas seguintes, adquirisse caráter de direito social.

Quadros (2003) explica que a revolução de 1930 gerou mudanças na organização da sociedade, que estava voltada para uma democracia populista e para a ideia do nacionalismo desenvolvimentista. Estas ocasionaram, também, mudanças na educação:

\begin{abstract}
A Revolução de 1930 representa um ponto de ruptura na sociedade brasileira, quando as formas de organização social, política e econômica da sociedade agrária tradicional, até então hegemônica, foram definitivamente abaladas e intensificou-se o processo de sua superação por um modus vivendi urbano-industrial que apresentava sinais de ascensão desde a década de 1920 (QUADROS, 2003, p. 22).
\end{abstract}

Inicialmente, com a Revolução de 1930 e o início da Segunda República, de certo modo, os educadores passaram a ser ouvidos e conferências nacionais de educação passaram a ser realizadas, conforme Paiva (1987). Porém, as iniciativas ainda eram poucas e a preocupação inicial do governo era quantitativa, não havendo o entendimento da educação como fator de mudança social.

Especialmente após a Constituição de $1934^{4}$ o Governo passou a se apresentar como promotor do desenvolvimento, o que refletiu no entendimento da educação como técnica social, preparatória

\footnotetext{
${ }^{4}$ Esta afirmou "o direito de todos e o dever do Estado para com a educação" (HADDAD; DI PIERRO, 2000, p. 110). Iniciou-se, a partir dela, a busca pelo ensino público, obrigatório, laico e gratuito, democratizando o ensino e responsabilizando a União por ele.
} 
para a atuação das pessoas na sociedade idealizada (que seria a sociedade desenvolvida) e "como instrumento de habilitação dos homens para a conquista desse futuro". (BEISIEGEL, 1974, p. 181).

Mais adiante, em 1940, segundo Paiva (1987), houve maiores discussões acerca da educação de jovens e adultos, muito em função do censo daquele ano que indicou que pouco mais da metade dos analfabetos tinha 18 anos ou mais. Haddad e Di Pierro (2000) explicam que o Estado brasileiro passou a organizar políticas públicas em prol da educação de jovens e adultos especialmente para atender às reivindicações populares e qualificar a força de trabalho.

Segundo Paiva (1987, p. 141), somente no final do Estado Novo, que ocorreu entre 1937 e 1945, a educação de adultos foi entendida "como um instrumento da redemocratização, como um problema que merecia tratamento especial e que polarizava as atenções pela possibilidade de utilização da educação em função de novos objetivos políticos".

Entre 1946 e 1964, na chamada República Populista, houve um crescimento nos índices de atendimento e de matrícula escolar, segundo Paiva (1987). A partir de 1945, as campanhas regionais e nacionais em prol da educação, que ganharam e perderam força desde o início do século, tiveram destaque. Ferraro (2009), assim como Haddad e Di Pierro (2000), dá ênfase à Campanha de Educação de Adolescentes e Adultos (CEAA), que iniciou em 1947, à Campanha Nacional de Educação Rural (CNER), de 1952, e à Campanha Nacional de Erradicação do Analfabetismo (CNEA), de 1958, entre outras que ocorreram em períodos próximos. A maioria delas, com o passar dos anos, e especialmente no governo de Juscelino Kubitschek (1956 a 1961), foram extintas por "sua falta de adequação às novas condições criadas pela política 'desenvolvimentista' [...]" (PAIVA, 1987, p. 178).

O final dos anos 1950 e início dos 1960 foi um período marcado por maiores iniciativas pela educação. Segundo Ferraro (2009), passou-se a valorizar a cultura popular e a participação do povo na sociedade, sendo realizado o planejamento de novas alternativas para os problemas educativos. Em meio a isso, com a ideia de aceleração do desenvolvimento econômico, a educação era entendida como formação de mão-de-obra assim como fator para a transformação social que se daria, principalmente, pela participação política.

Com isso, surgiram os movimentos de educação popular, em função dos quais a educação de adultos também recebeu maior atenção. Ferraro (2009) comenta que, especialmente, de 1958 a março de 1964 ocorreram vários movimentos sociais ligados à alfabetização e à educação popular, referindose, também, à educação de adultos; e foram organizadas várias campanhas educacionais (regionais e nacionais).

Um importante acontecimento foi o II Congresso Nacional de Educação de Adultos, no Rio de Janeiro, em julho de 1958. Nesta ocasião, segundo Haddad e Di Pierro (2000), percebeu-se uma preocupação referente à educação de adultos e à necessidade de repensar as formas com as quais era colocada em prática. As discussões do congresso indicaram os problemas das campanhas já realizadas e estes foram tomados como ponto de partida para pensar as mudanças necessárias na educação de adultos "de modo a torná-la funcional à sociedade brasileira em transformação". (PAIVA, 1987, p. 208). Novas ideias pedagógicas emergiram, predominando o entendimento da educação de adultos como instrumento de transformação social. 
Marcava o Congresso o início de um novo período na educação de adultos no Brasil, aquele que se caracterizou pela intensa busca de maior eficiência metodológica e por inovações importantes nesse terreno, pela reintrodução da reflexão sobre o social no pensamento pedagógico brasileiro e pelos esforços realizados pelos mais diversos grupos em favor da educação da população adulta para a participação na vida política da Nação (PAIVA, 1987, p. 213).

Novas possibilidades de métodos educativos também foram discutidas e o Congresso abriu espaço para a transformação do pensamento pedagógico, que se voltou para a reflexão sobre as questões sociais e políticas vividas no país. Neste sentido, Freitas e Biccas (2009, p. 226) explicam que:

A discussão sobre a educação continuava conectada ao tema do desenvolvimento, bandeira de JK, mas a partir de então, adquiriu também outra formulação, voltando-se para a defesa de ações direcionadas à formação da consciência do povo brasileiro, do ponto de vista individual e coletivo, particularmente da população mais pobre, que acumulava séculos de preterição.

Este pensamento foi sendo ampliado na medida em que os movimentos para a educação popular eram realizados. A educação de adultos passou, então, a ser pensada como educação política permeada pela reflexão sobre a realidade, segundo Haddad e Di Pierro (2000). Os autores comentam que "[a]s diversas propostas ideológicas, principalmente a do nacional-desenvolvimentismo, a do pensamento renovador cristão e a do Partido Comunista, acabaram por ser pano de fundo de uma nova forma de pensar a educação de adultos". (HADDAD; DI PIERRO, 2000, p. 113).

Em meio aos outros grupos que teciam diferentes ideias, "[c]ristãos e marxistas, principalmente, empenham-se em movimentos de educação de adultos que enfatizam a importância da cultura popular e sua difusão" (PAIVA, 1987, p. 164). Ainda no que se refere aos cristãos, emergia neste período um maior interesse, em especial, da Igreja Católica, pela educação das massas, o que pôde ser percebido por meio das diferentes práticas para a educação popular por ela desenvolvidas naquele período, em meio às iniciativas governamentais (ou mesmo junto a elas).

Os encontros e campanhas promovidos no final dos anos 1950 e início dos anos 1960 referiamse primordialmente à educação de adultos, no viés da educação popular, segundo Paiva (1987). Um exemplo é o I Encontro Nacional de Alfabetização e Cultura Popular, realizado em Recife, em 1963. Este tinha a intenção de promover um debate sobre as experiências de alfabetização que estavam sendo realizadas no Brasil visando uma articulação nacional. Ainda segundo Paiva (1987), a troca de experiências e o levantamento dos diferentes movimentos existentes foram pontos principais do congresso. O encontro foi uma das influências para as diretrizes do Programa Nacional de Alfabetização, criado posteriormente.

Freire (1992, p. 279) explica que os anos 1960 foram de maior presença e reivindicação popular e que é em meio a este "[...] momento histórico, social e político do país, que emerge uma série de iniciativas no campo que se chamou, em primeiro lugar, educação de adultos e, depois, cultura popular". A educação popular tinha a intenção de conscientizar, de auxiliar no entendimento da realidade política, social, econômica e cultural na qual o povo estava vivendo. Conhecendo sua realidade, os educandos poderiam entender-se como sujeitos que a fazem, bem como engajar-se em lutas por sua transformação. Esta educação popular visava uma conscientização que acarretasse ação 
política; estava pautada no processo político-pedagógico, segundo Ferraro (2009); e tinha como característica a crítica à educação bancária.

A educação precisava integrar as pessoas no projeto social de desenvolvimento que estava sendo construído para que pudessem nele atuar. Freire (2003) entendia como necessária para a sociedade em trânsito uma organicidade, uma integração entre a realidade cultural e os processos educativos para que esta "inexperiência democrática" (FREIRE, 2003) fosse superada por meio da participação popular. "A presença das massas era entendida como fator e condição de possibilidade de realização de uma próspera sociedade nacional capitalista desenvolvida, independente e, por isso mesmo, autêntica, senhora de seus destinos" (BEISIEGEL, 1982, p. 65).

A educação crítica seria o meio que possibilitaria uma mudança de atitude, e esta, por sua vez, tornaria possível a transformação da realidade colonizada. Surgia, naquela época, um movimento de resistência e mudança em relação aos objetivos da educação, pois era fundamental que esta "[...] não esquecendo ou desconhecendo as condições culturológicas de nossa formação paternalista, vertical, por tudo isso antidemocrática, não esquecesse também e sobretudo as condições novas da atualidade" (FREIRE, 2000a, p. 99).

Assim, a educação popular seria uma educação para a reflexão do educando sobre si mesmo, sobre sua realidade e a sua ação nesta, enquanto sujeito histórico e dela produtor. Com esta intenção, a educação popular apresentava uma crítica à ordem social vigente e tornava-se uma possibilidade para a libertação. Buscando suas origens na cultura produzida pelo povo, tinha a intenção de que este conhecesse sua historicidade, entendendo-se como produtor dela, da cultura e das relações por elas permeadas (FREIRE 2000a; 2003).

Neste período, alguns movimentos de educação popular tornaram-se mais ativos. Os Centros Populares de Cultura (CPC) iniciaram sua atuação a partir de 1962, tendo como ponto de partida um CPC criado pela União Nacional dos Estudantes, em 1961. Estes centros trabalhavam com o teatro crítico, que apresentava um discurso político, levado às classes populares, caracterizando-se como espaços de educação não escolar. A intenção era promover a conscientização das classes oprimidas: "[...] os diversos CPCs uniam-se em torno do objetivo principal, o de contribuir para o processo de transformação da realidade brasileira, principalmente através de uma arte didática de conteúdo político" (PAIVA, 1987, p. 233).

Outro exemplo é o Movimento de Cultura Popular (MCP). Este tinha, desde o início, a intenção principal de conscientizar por meio da alfabetização e da educação de base (PAIVA, 1987). A participação consciente, ativa e, por isso, libertadora era a finalidade das atividades do MCP, que tinha como influência o pensamento cristão. A compreensão da cultura popular era fundamental para a sistematização do trabalho de análise crítica da realidade realizado com o povo, numa relação mediada pelo diálogo (FREIRE, 2000a).

Junto a outras atividades, a alfabetização era realizada com a integração dos educandos em sua realidade cultural e política. O MCP de Pernambuco contou com a colaboração de Paulo Freire em algumas de suas atividades e foi importante para a elaboração de suas práticas posteriores. Paiva (1987) e Beisiegel (1974) indicam, inclusive, que a partir do MCP e suas mobilizações Paulo Freire refletiu sobre novas possibilidades para a educação e organizou o "Método Paulo Freire de 
Alfabetização de Adultos" (BEISIEGEL, 1974, p. 164), que tornou-se conhecido nacionalmente pela divulgação da experiência realizada em Angicos - RN. Como a proposta aproximava-se do viés das expectativas do governo federal ${ }^{5}$, ela passou a ser organizada em parceria com o Ministério da Educação e Cultura, com o objetivo de ser levada a todo o Brasil.

Assim, em meio aos encontros, movimentos e campanhas pela educação popular e pela alfabetização de adultos, Paulo de Tarso, ministro da educação, convidou Paulo Freire para coordenar atividades de alfabetização junto ao Ministério da Educação e Cultura, em julho de 1963 e o Programa Nacional de Alfabetização foi instituído por decreto em 21 de Janeiro de 1964 (BEISIEGEL, 1974).

Há indícios ${ }^{6}$ de que alguns governos estaduais e municipais se mobilizaram antes mesmo de receberem os auxílios federais que seriam disponibilizados em função do convênio. O programa de alfabetização organizado por Paulo Freire se espalhou pelo país, com a promessa de uma alfabetização rápida e eficiente, em meio ao convite à reflexão e participação na sociedade. Tudo isso foi possível em função das características desta proposta.

\section{OS CÍRCULOS DE CULTURA: A PROPOSTA DE EDUCAÇÃO POPULAR DE PAULO FREIRE}

Antes mesmo de preocupar-se com a alfabetização propriamente, Paulo Freire tinha como foco a participação popular na tomada de decisões. A liberdade era a matriz da proposta e deveria estar evidenciada nas ações educativas. "Pensávamos numa alfabetização que fosse em si um ato de criação, capaz de desencadear outros atos criadores" (FREIRE, 2000a, p. 112). No processo de alfabetização era dada ênfase à significação da linguagem e da palavra, pois, para Freire era preciso ler a palavra para pronunciar o mundo.

Por isso o processo de alfabetização tinha como ponto fundamental a reflexão e o diálogo sobre a realidade, sobre as pessoas como criadoras de cultura, capazes de pronunciar e transformar o mundo. Assim, o processo de alfabetização fazia-se em meio a um processo de conscientização para a transformação (para a re-construção da sociedade de acordo com as características desejadas para seu futuro em desenvolvimento). Paulo Freire organizou uma nova forma de educação, na qual os educandos passavam a reconhecer a si próprios como criadores de cultura e se educavam por meio do diálogo.

Os Círculos de Cultura eram espaços em que dialogicamente se ensinava e se aprendia. Em que se conhecia em lugar de se fazer transferência de conhecimento. Em que se produzia conhecimento em lugar da justaposição ou superposição de conhecimento feitas pelo educador a ou sobre o educando. Em que se construíam novas hipóteses de leitura de mundo (FREIRE, 2015, p. 192).

Sendo a educação um ato coletivo, um dos pressupostos desta prática educativa era uma diferente organização dos educandos no espaço onde os círculos de cultura aconteceriam. Como o

\footnotetext{
${ }^{5}$ A experiência de Angicos ocorreu em 1963 e contou, em seu encerramento, com a presença com a presença de João Goulart, presidente do Brasil na ocasião, fomentando a promoção nacional do programa de alfabetização realizado.

6 O Rio Grande do Sul é um exemplo de Estado que mobilizou-se para conhecer e realizar o programa de alfabetização operado em Angicos, como demonstram reportagens de jornais da época. Um exemplo é o Correio do Povo, que traz diversas reportagens, especialmente em 1963, informando que "A vinda de Paulo Freire possibilitará a Porto Alegre e ao Rio Grande o emprego de seu método, assim como atualmente se faz em Recife, Natal, João Pessoa e Florianópolis." (CORREIO DO POVO, 28/06/63, p. 10).
} 
próprio nome remete, os educandos/participantes e o animador cultural/coordenador ficavam juntos em um círculo que tinha como objetivo ser um espaço de partilha de conhecimentos e de diálogo. Este e a participação dos educandos eram condições essenciais dos círculos de cultura.

A proposta partia da experiência vivida, da problematização da realidade concreta. Sendo assim, para a elaboração dos círculos de cultura, na primeira fase (FREIRE, 2000a), o animador cultural/coordenador buscava conhecer a comunidade, inserindo-se nela e dialogando com os educandos para fazer a pesquisa de seu universo vocabular e seu universo temático, a partir do qual eles iriam debater. A investigação daria o norte para a aprendizagem na qual a fala tornar-se-ia escrita.

O universo local estava sendo pesquisado por meio do contato com a realidade que o animador cultural/coordenador fazia e do diálogo com os educandos/participantes. A temática inicial deste diálogo seria a cultura (o que é, como os educandos/participantes com ela interagem, como a formam e dela se formam, etc.) (FREIRE, 2000a).

Posteriormente, a cultura local era, então, introduzida ao debate. "A segunda fase é constituída pela escolha das palavras, selecionadas do universo vocabular pesquisado" (FREIRE, 2000a, p. 121). As palavras escolhidas, palavras-geradoras, eram selecionadas gradualmente a partir da riqueza fonêmica e temática (vinculação com a realidade cultural). Elas eram usadas para a leitura da língua escrita, mas também, para a releitura coletiva da realidade social.

Começava, então uma terceira fase: a criação de situações existenciais, compreendidas como "[...] situações-problemas, codificadas, guardando em si elementos que serão descodificados pelos grupos, com a colaboração do coordenador" (FREIRE, 2000a, p. 122). A quarta fase, seria a elaboração de fichas-roteiro e a quinta fase seria a montagem de fichas com a decomposição fonêmica das palavras-geradoras (FREIRE, 2000a).

Os assuntos escolhidos no grupo eram "[...] esquematizados e, com ajudas visuais, apresentados aos grupos de forma dialogal" (FREIRE, 2000a, p. 111). Nas fichas de cultura (BRANDÃO, 1991; BEISIEGEL, 1982) que continham as imagens representando situações existenciais, as palavras-geradoras (codificadas pelos desenhos das fichas) passavam a ser descodificadas pelo diálogo com a reflexão sobre seu significado e a problematização da realidade.

A descodificação era realizada dialeticamente pelo animador/coordenador e pelos educandos em conjunto e, segundo Freire (1983), era o momento de (i) tomada de consciência, (ii) descrição dos elementos da codificação, (iii) apreensão da realidade, da situação codificada e (iv) análise crítica do que a codificação representa. Era um dos momentos em que se fazia a leitura da realidade. Nele, o animador cultural/coordenador deveria problematizar a situação existencial fazendo perguntas aos educandos e auxiliando-os a superar formas ingênuas dessa leitura. Com o tempo, a intenção era que os próprios educandos conduzissem a maior parte da discussão e da reflexão, entendendo-se como criadores de cultura.

Feita a problematização a partir das imagens, as fichas com as palavras-geradoras eram também apresentadas e o debate continuava, com o reconhecimento da palavra escrita. Relacionavase imagem e palavra para, posteriormente, trabalhar somente com a palavra. Depois, as palavrasgeradoras eram apresentadas com as sílabas separadas. As famílias fonêmicas da palavra eram dispostas separadamente e, em seguida, em conjunto. 
Esta era a ficha da descoberta, que tinha este nome pois, ao observá-la visualmente, ler as sílabas (com o auxílio do animador cultural/coordenador), perceber o processo de formação das palavras e apropriar-se criticamente dele, os educandos passavam a combinar as sílabas, 'descobrindo' outras palavras. O educador/coordenador realizava um trabalho de reconhecimento das letras e sílabas relacionando-as com seu 'som'.

Cada nova palavra gerava um novo debate, uma nova problematização. E, aos poucos, todas as palavras-geradoras, inicialmente selecionadas, eram utilizadas. Compreendendo este processo e fazendo associações, frases e pequenos textos também passavam a ser formulados. Este era um processo de escrita e leitura sempre permeado pela discussão, pelo debate, no qual a intenção era uma participação cada vez maior dos educandos em seu próprio processo de aprendizagem.

Buscava-se a construção de uma consciência crítica, a partir da problematização do universo local descoberto. A leitura e reflexão sobre a realidade local impulsionavam e abriam as portas para uma reflexão que partia dela, mas ia além. A reflexão crítica e a problematização perpassavam toda a aprendizagem da leitura da realidade e da leitura da palavra e o objetivo final era que os educandos desenvolvessem seu processo de conscientização. Rosas (2003, p. LXXII), explica que:

[n]o MCP, como, de resto, nos demais movimentos dos anos 60 (MEB, campanha De Pé no Chão Também se Aprende a Ler, CTC...), alfabetização queria dizer conscientização. Conscientização, palavra-chave no discurso de Paulo Freire. Perguntava-se: alfabetizar, alfabetizar-se, para quê? Deveria haver um motivo importante para justificar o esforço a despender. E este motivo era alfabetizar-se para ler e entender. Pensar e compreender seus problemas [...].

Esta proposta de prática educativa foi realizada a partir da concepção de educação que Paulo Freire desenvolveu em função da realidade na qual estava inserido. Por isso, abordamos aspectos de sua concepção de educação, no item a seguir, com a intenção de disponibilizarmos mais elementos que contribuam para o entendimento da proposta do educador.

\section{EDUCAÇÃO EM PAULO FREIRE}

Freire (2000a) explica que o Brasil passava por um momento de transição. "Daí que não fosse possível ao educador, então, mais do que antes, discutir o seu tema específico, desligado do tecido geral do novo clima cultural que se instalava, como se pudesse ele operar isoladamente (FREIRE, 2000a, p. 54)". Neste contexto de transição cultural no qual estavam emergindo movimentos populares, Paulo Freire pensou uma educação que, mais do que não poder se desvincular da realidade precisava ser um processo que contribuísse com a maneira com a qual as pessoas iriam se (re)organizar no novo cenário que vinha se formando. Segundo Beisiegel (1982, p. 91) "[...] o processo educativo, em condições institucionais (faseológicas) propícias, podia por sua vez levar à formação da mente orientada para a construção da democracia e para a preservação das formas democráticas de vida".

Para isso, precisava ser uma educação crítica, para inserção social, contrária à massificação, à acomodação e ao assistencialismo. A educação teria papel de auxiliar as pessoas a criarem um 
sentimento de responsabilidade em relação à realidade e, com isso, participar nas construções da vida coletiva, através da reflexão crítica sobre si mesmas e sobre o mundo (FREIRE, 2000a).

Entendendo que o problema da educação era a "inadequacidade com o clima cultural" (FREIRE, 2003 , p. 79), o educador fez, então, uma crítica ao modelo educacional que continuava sendo autoritário, centralizador, vertical, sem possibilidade para a democracia. Em lugar de uma educação da palavra esvaziada de sentido, desvinculada da vida, memorizada e reprodutora do modelo colonialista e da ordem social injusta, o educador entendia que a educação precisava ser um momento de reflexão sobre a realidade e sobre as possibilidades de ação para sua transformação. Era necessária uma educação para o desenvolvimento, para a democracia e, portanto, para o diálogo, para a construção de uma consciência coletiva, para a criticidade e para a conscientização.

Tomando-a como única possibilidade para a transformação social, para a reforma política, Paulo Freire buscou formas de reorganizar a educação a partir da realidade brasileira. Contrariando o ideal opressor de sua época, o educador dava voz aos oprimidos, visando o poder de participação na tomada de decisões sobre suas próprias vidas, visando a democratização. Com ele, o ato educativo passou a ter um caráter revolucionário, onde a reflexão deixava de ser privilégio de determinada classe e, quando dialógica e problematizadora, buscava a libertação que se dá pela práxis (reflexão e ação) transformadora.

Assim como outras ideias que foram formuladas na mesma época, as ideias de Paulo Freire vinham de experiências com os grupos populares e sofriam as influências do pensamento de teóricos franceses, da visão cristã de mundo, além do pensamento isebiano sobre a consciência nacional (BEISIEGEL, 1982). A partir destas influências, Paulo Freire pensou a questão da vivência da democracia nas decisões do povo: as decisões para o povo deveriam ser tomadas com o povo, na sua ação participativa desde o cotidiano. A democracia, antes de ser forma política é forma de vida, segundo Freire (2003), e se caracteriza por uma participação consciente. Mas essa consciência não se desenvolve num espaço onde não há diálogo, debate, problematização da realidade e uma verdadeira participação.

Desde Educação e atualidade brasileira, Freire escrevia que a escola precisaria estar próxima de sua realidade local. "O seu enraizamento nas condições locais e regionais, sem esquecer os aspectos nacionais, é o que possibilitará o seu trabalho de identificar seu educando com seu tempo e seu espaço" (FREIRE, 2003, p. 84). O educador enfatizava a vida comunitária entrando na escola, e entendia que o contexto local é o ponto de partida. Sem esquecer das individualidades, buscava uma consciência de grupo. Entendia que era necessário reorganizar o processo educacional de acordo com as características da realidade (BEISIEGEL, 1974).

O educador frisava constantemente a necessidade de uma educação para a responsabilidade social e política, em virtude do contexto de inexperiência democrática. A partir das ideias isebianas, Freire entendia que a conscientização das pessoas ou a transição da consciência ingênua para a crítica (em seus estágios) era possível, mas não se daria de forma automática, junto ao movimento de transição da sociedade, pois "[...] a incipiente emersão das massas com maior probabilidade tendia a produzir a massificação das consciências" (BEISIEGEL, 1982, p. 59). 
Neste sentido, Freire (2003) foi fazendo uma crítica ao modelo de educação que predominava naquela época, uma educação do discurso, da passividade, do assistencialismo, da memorização, da acomodação, da recepção, aceitação e repetição de ideias desconexas. O educador escreveu sobre uma educação para aprender a aprender, para a pesquisa, uma educação da conexão com a vida, do diálogo, da participação democrática, da problematização, da mudança de atitude.

Nas escolas, porém, predominava um modelo educacional que, posteriormente, o educador chamou 'bancário' e que não possibilitaria esta democratização. "Não será possível, repita-se, com uma escola assim, formarmos homens que se integrem neste impulso de democratização que nos caracteriza atualmente" (FREIRE, 2003, p. 90). Paulo Freire fez um movimento para pensar as necessidades da época e entendeu que a educação possibilitaria a transformação necessária ao ensinar o povo a refletir e a participar. Por tudo isso organizou os círculos de cultura, mencionados anteriormente.

\section{TENSÕES E DIVERGÊNCIAS}

Em meio a um movimento no qual havia apoio à mobilização para que ocorressem os círculos de cultura, também havia críticas sendo tecidas, indicando tensões e divergências sobre o pensamento existente. Ao mesmo tempo em que havia a preocupação com a transformação social, alguns interesses políticos passaram a permear a realização dos círculos de cultura, dando-os caráter políticopartidário (BEISIEGEL, 1982). A aproximação com o governo de João Goulart gerou um destes outros sentidos para a proposta de alfabetização, tendo a intenção de angariar votos da população que ainda não sabia ler e escrever e, portanto, não participava das eleições. Ainda, houve aqueles que entenderam a proposta de alfabetização como uma proposta comunista. Esse conjunto diverso de representações circulou pela imprensa da época, num jogo de tensionamentos e divergências que deixavam explicita a polarização vivida naquele momento histórico.

A busca nos periódicos sinaliza para as diversas representações sobre os círculos de cultura, sendo que muitas foram emitidas em meio ao entusiasmo em favor de sua realização. Por isso, trazemos, aqui, reportagens que indicam estas tensões entre opiniões a respeito do 'Método Paulo Freire'. Como um primeiro exemplo apresentamos uma reportagem do conhecido jornal gaúcho Correio do Povo, em edição de dezembro de 1963. Nela, as críticas são sobre (i) os aspectos técnicos do programa de alfabetização, a respeito dos quais há a indicação de que "nada oferece de novo"; e (ii) as questões ideológicas que apresentava, em função de estar permeado pela preocupação com temas sociais, tornando-se uma ameaça bolchevista e comunista. 
Figura 1 - Reportagem do Jornal Correio do Povo, RS, 27/12/1963

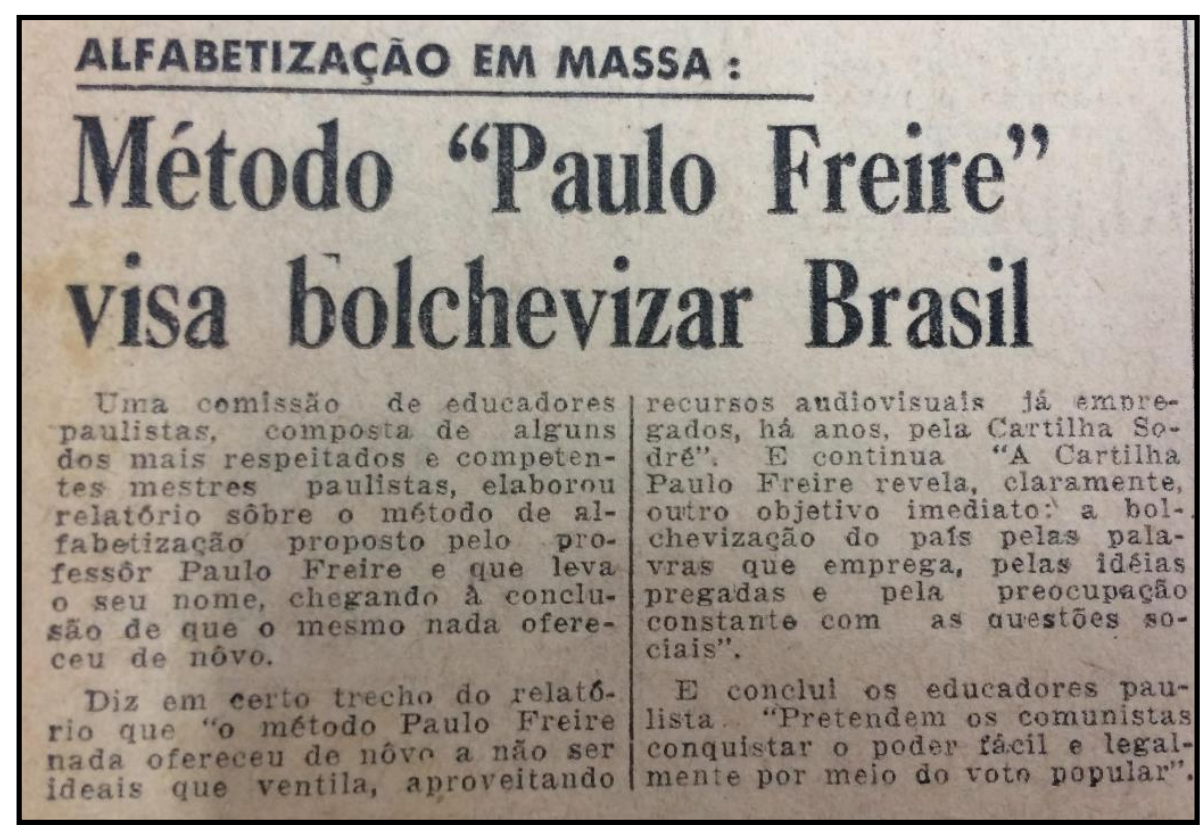

Fonte: Jornal Correio do Povo, 27/12/1963, p. 12.

Em outro recorte, poucos meses depois, a representação é distinta, mesmo sendo o mesmo 'Método Paulo Freire'. São produções de significação em disputa, num momento político do país o qual é importante ainda a ser pensado do ponto de vista histórico. A seguir afirma-se que 'só os obscurantistas extremados combatem campanha do MEC', referindo-se ao 'Método Paulo Freire' que seria adotado no Programa Nacional de Alfabetização. Mobiliza exemplos de apoio ao método provenientes da Igreja e dos 'americanos', leia-se estadunidenses. 
Figura 2 - Reportagem do Jornal O Semanário, Rio de Janeiro, de 06 a 09 de fevereiro de 1964.

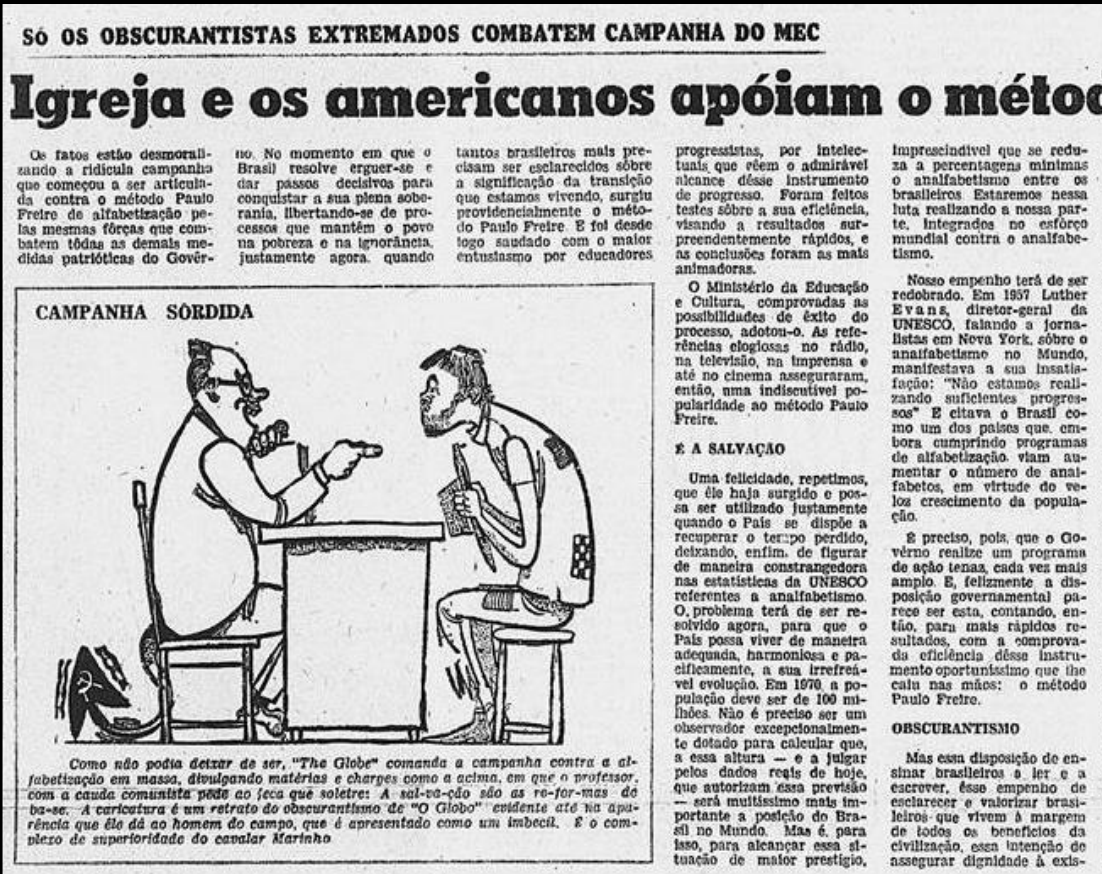

Rêde Ferroviária Federal: efetiva participação no desenvolvimento econômico e social do país
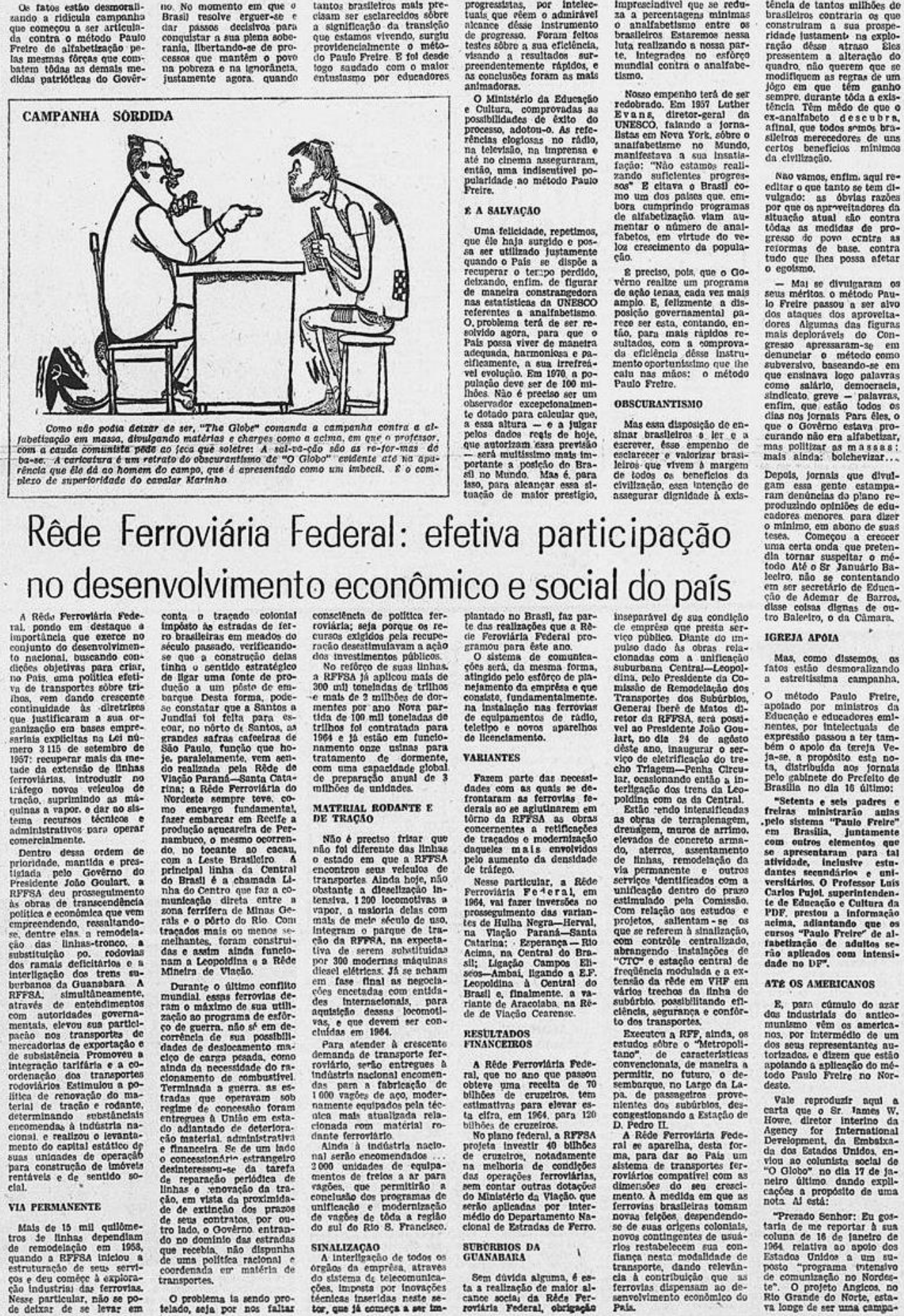

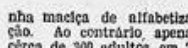

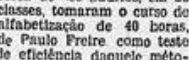

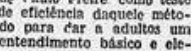

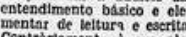

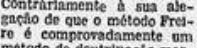

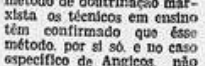

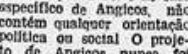

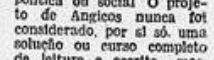

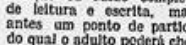

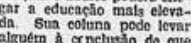

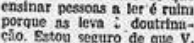

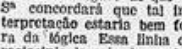

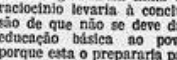

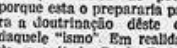

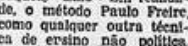

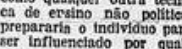

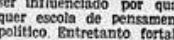

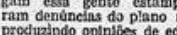

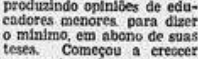

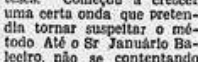

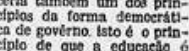

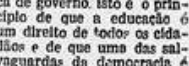

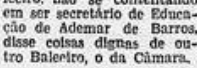
tro Balerito, o

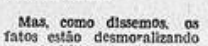

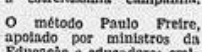

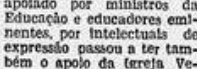

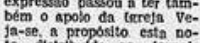

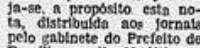

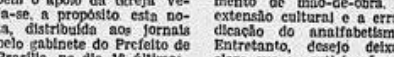

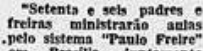

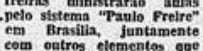

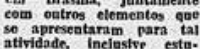

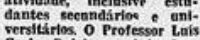

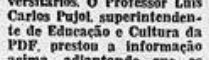

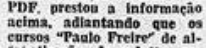

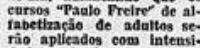
Aтz OS AMERricasos

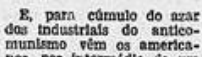

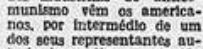

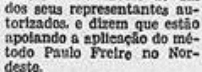

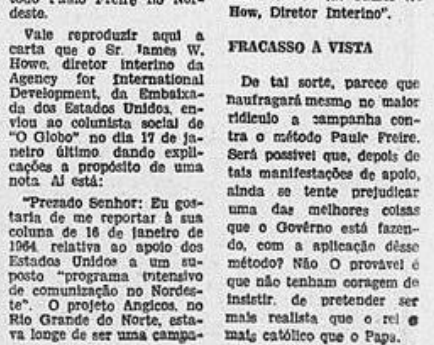

Fonte: Jornal O Semanário, 06 a 09/02/1964, p. 07.

Outro exemplo está no Jornal do Dia, em reportagem de 26 de novembro de 1963, quando este, sutilmente, faz uma crítica indicando, sem maiores explicações, que "[...] a UMESPA se dispõe a 
incentivar ainda mais a Campanha de alfabetização, para o que empregarão o método Paulo Freire, sem a 'fanatização', que leva o nome de politização" (JORNAL DO DIA, 26/11/1963, p. 6). Esta reportagem pode ser um indício de aceite da metodologia utilizada na realização dos círculos de cultura, mas sofrendo algumas modificações que o deixariam livre da parte que era entendida como doutrinadora.

Outro momento no qual críticas são expressas é um texto de um colaborador, Gustavo Corção, escrito especialmente para o Correio do Povo. O texto inicia debatendo sobre fenômenos criados para explorar as pessoas e toma os analfabetos como uma "mina de exploráveis". O autor expressa que o método foi criado para agradar o governo e aos que pensam as reformas de base como mágica para o Brasil. "Ou então selecionam-se as duas espécies de gente, e é com essa combinação, bobinhos e espertalhões, que se pretende erguer o nível do homem brasileiro!!!" (CORREIO DO POVO, 16/01/1964, p. 4).

Em meio às críticas, outras opiniões demonstravam apoio ao Programa Nacional de Alfabetização, como explicita a reportagem a seguir. 
Figura 3 - Reportagem no Jornal 'Última Hora', Rio de Janeiro, início da aplicação do 'Método Paulo Freire', em 11 de março de 1964.

\section{PLANO QUE COMEÇA DIA 20 VAI ALFABETIZAR 400 MIL ADULTOS}

REPORTAGEM DE NELSON SILVA

A POS tres meses de orzanizacio e prepara 4 cáo, comecurâo a funciobar dia 20, os ci too mill adultos do analrabetimo, arraticar de um ano, resunite anunciou o Coordensidor Regional Aron Abond no SEC, em entrevisa a

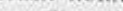

estáo terminando sebs cursos gobre o Metodo Paulo Freire de Alfabetizasao e is estas sendo instaiados os 600 cineulos culturas, once as aulas nu primira ctapa. Na elapa rinal, o oumbero
déssen cinculos vetă cievado para 2 ini, levando

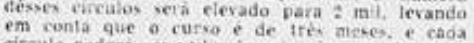
circulo podera ser utilizado tice irzes em 9 meses

Baixada é Foco

cou Coordenador fiegional Amon Abund exp! cta intralando o nucies bay ma Eaisada Flum

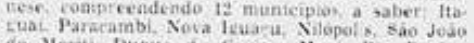

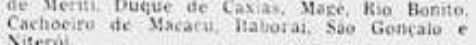
Justificande a escoiba dínere locas, dectarau

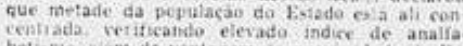

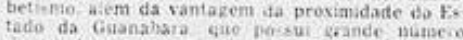
de estudantes recrutaveis. e facil dade nas vias de Outro nucied devere ser montado drintro de
cois meses em Compos etr condicoes de alfathe

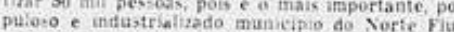
minener que proporciona condicues paia umplan. tacas, com relativa facilidade de uma slabeoorde

\section{Trabalho Realizado}

o Programa Nacional de Alrabitizacan rexil

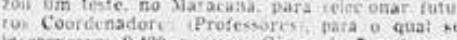
pareceram 2 prove das quais foram selecionada.

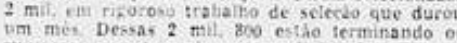
euinos que so desarto efla condicoes de aplicar:

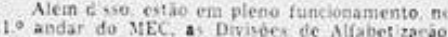
Mobtlizacto e Administiasao. A primeira of encas

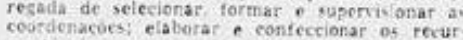
criteonices para A Alrabetizscao e perzuntan tezundo a pecularifades do PNA e das area O trabsilho de miobilizar tóda a populacáo das a Divisio te Mobilizacso, que tems o enca so de recrutar on snalfabetos, folicitar ofertas de 10

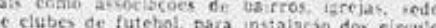

de cultura e, ainda dar susteatacao social aos $\mathrm{CC}$

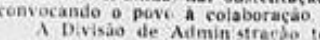
complesis tarefas da sustentacáo adminisitrativa

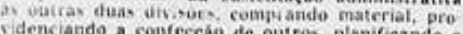
contrelasado todo o sistema de transportes de ma. Faralelamente ao tratailho do Coordenador Kegional. Iuscions o Conseliho de Planejamento
composto do Coordenador kekionat, dos trés Co erdenadores das Divisdos e da Tesourciro.

Para a preparacăo dos Coordenadores, foram ormados 60 Supervisores no primeiro curso. Jh realizado, e majs 60 estào terminando o segundio Una equipe especializada preparou e confee urra tita de celutoide remellente. de cine de

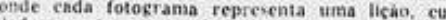
dadosamente prerarada, fotografada e revelada especiais, com uma facc brance quadros nesros Dificuldades

O PNA fol eriado por decreto do President alo todo o territorio nacional sendo gue a Comis eapecial criaca por decreto e presidida nelo hixtro da Educasio. da comecou a implantar on

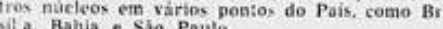
As dificuldade a superar, contudo, sào mui aita primecira, e taisez maix importante, $e$ putiese orientarsoc o ouc implica cm dizer que tudo que esta sendo feito $e$ criaça da equipe eul (unctoramento.

O PNA dispóe apenas de 16 viaturas para to a. on scrviso, quardo serisin necessirias, so pat

F. as vaturas sào utilizadas para o trans potte co pessoa e para a mobilizacá do poro c de persunsáo direta, de casa em casa conaplo nientaco com o sarvicu die allo falante instolnd wos carros, megafones, cartazes e ate pichamento. ara motivacao perieita.

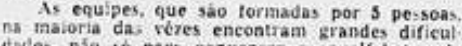
tives. na so parta convencer or analfavetos do cura mos também para convencé los de que ôles têm condicoes de sair da obscuridade. A falts de cnergia eletrica e outro grande probiema, que bbripa a improvisacea de refursox, principalmente

Outra difieuldade e a aecesbidade da forma de quadros ecm srande rapicer assim conso oficado smultaneamente.

- Nó fósse a extrena nex bilidade da equifido emperransento. Somos obrígados tivesse so periedica do norso trabalho $c$ o entusiarmo ten saperado tudo Todos trabuiltam mais de to ho ras disto piaro de um ino. para prestaciso de servicos $D$. trelanto, a ecriezo de que esiamos visendo malor experiencia cuitual do Brasil, em todos tempos, inspulsions a equipe $e$ nho induz at Aron Abend. deelarou o Coordenador Regio

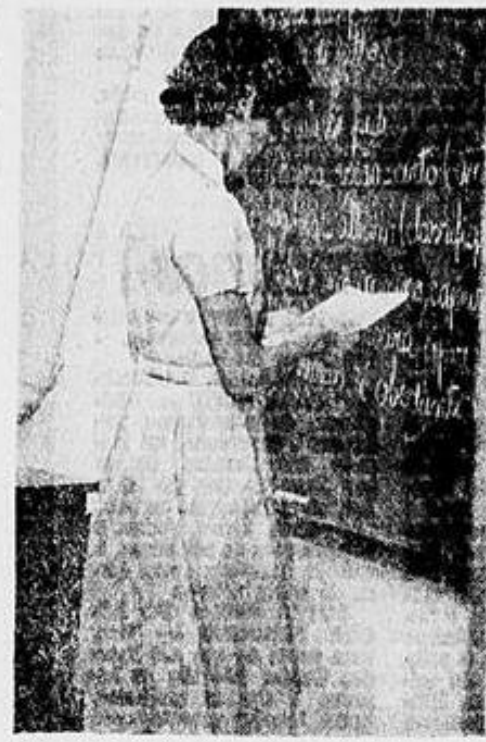

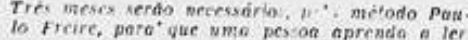

Praças de Cultura

Alem désse trahalho. P PNA tambem vai di rizirse so semialiabetizacio e alfabetizado, obje de insolachar o sea indice cuiturat. hia projeto mas pracas públoss onde cuncionara cm gaipoces de eultura, seráo apresentados testros de mario netes, fantoches, sombras, e o próprio povo apren dera sta uthizacáo para exposicòes e festas. Paralelamente nos efrecilos de cultura, o Pla de pacional de Airabetzaça realizara pesquisas ge pas após o termino do ullimo curse dival

Entre os inscritos para ns circulos de cultura a mais ldoen é ums senhora de as anos que a cruipe conscau u eonvencer da necesidade de

\section{So Decreto}

Finalmente, o Coordenador Aron Abend dis. ie que muitos furcionários putlices fazom parte sistentemente repuistadox, atravós, de oficios, in foram liberados por suas reparticóes. Presidente Joào Goulart, que ja cua sendo provideneiato situacdo Felizmente a natoria do resolver a da equipe fo:am recrutados na moximento ettu. dantil, que tem se mostrado celcino ideal de pes soat para o tipo de trabatho a que estamos en

Fonte: Jornal 'A Última Hora', 11/03/1964, p. 04

É relevante notar a data da notícia - veiculada em 11 de março de 1964 - vinte dias depois, o golpe civil-militar concretizaria outros rumos para a educação, em especial para a alfabetização de 
adultos e o Programa Nacional de Alfabetização, que iniciaria com os projetos piloto no Rio de Janeiro e Sergipe, foi suspenso. No caso específico do Rio de Janeiro as notícias posteriores seriam de que o método não fora aplicado 7 .

Do mesmo modo que havia intenções diferentes para a realização dos círculos de cultura (transformação social e angariação de votos), haviam também opiniões favoráveis e contrárias à realização deles. De um lado, eram entendidos como processo de conscientização e, de outro, de "comunização". Tais assertivas podem ser pensadas como representações em disputa, num momento em que a desestabilização do governo Jango se fazia sob diferentes críticas ${ }^{8}$.

É possível pensar que o 'Método Paulo Freire', ao mesmo tempo em que ganhou reconhecimento por parte do Ministério da Educação e Cultura (e talvez por conta disso), e passou a ser nacional e internacionalmente visto como efetivo na promoção da alfabetização, da conscientização e da politização das classes populares, também foi representado como subversivo, doutrinador, esquerdista, comunista e bolchevique - todos qualificativos localizados na imprensa jornalística da época.

\section{CONCLUSÃO}

A prática de educação popular organizada por Paulo Freire foi pensada a partir da realidade histórica do contexto brasileiro. Nos círculos de cultura, realizava-se um processo de leitura e reflexão sobre a realidade e de leitura das palavras que pelo contexto dos educandos perpassavam. Era uma proposta de conscientização, de participação e para que os educandos pudessem assumir papéis ativos e críticos junto ao contexto em que se encontravam, tomando seu lugar de sujeitos deste e reorganizando-o a partir de uma nova prática: a práxis transformadora. Apesar de breve, esta experiência mobilizou muitas pessoas e instituições em prol da educação popular, mostrando sua importância. Weffort (2000, p. 17), explica que

[...] a experiência foi plenamente vitoriosa como um teste: dezenas de milhares de trabalhadores alfabetizados em alguns poucos meses e a preparação de alguns milhares de jovens e estudantes para as tarefas de coordenação. Ficou a semente. Ademais, a experiência teve êxito porque - apesar de sua especificidade nacional e de sua conexão com uma etapa determinada da história brasileira - pode hoje começar a ser estudada em sua significação mais ampla, que transcende os marcos deste período e as próprias fronteiras do País.

Com este objetivo, escrevemos este texto, que buscou apresentar um breve histórico do contexto brasileiro, no que se refere a alguns aspectos da organização da educação, o surgimento da educação popular e uma breve síntese sobre o programa de alfabetização proposto por Paulo Freire tomando-o como exemplo de prática educacional popular. É tempo de significar a prática educacional

\footnotetext{
7 A modo de exemplificação, no também Jornal 'A Última Hora' de 16 de abril de 1964, em pequena nota na capa, divulgou-se: "Método já condenado. O Ministro da Educação, Flávio de Lacerda, declarou à imprensa que seu primeiro ato na chefia da pasta será a proibição do método Paulo Freire de alfabetização de adultos - método que seu autor afirma ser capaz de ensinar um adulto a ler e a escrever em 40h" (Jornal A Última Hora, 16/04/1964, capa).

8 Não é demais lembrar que "nos últimos dias de março [1964] intensificaram-se as atividades conspiratórias, envolvendo oficiaisgenerais, oficiais superiores, governadores, parlamentares e empresários. Muitos deles vinham participando de prolongada campanha de desestabilização do governo João Goulart, sobretudo através de atividades de propaganda política variada, capitaneadas pelo Ipes (Instituto de Pesquisas e Estudos Sociais) e pelo Ibad (Instituto Brasileiro de Ação Democrática), que afirmavam a incompetência do governo e sua tendência esquerdista" (FICO, 2004, p. 15).
} 
freireana dos anos 1960, compreender as diferentes representações em disputa naquele momento histórico para pensar em novas práticas educacionais que podem tomá-la como ponto de partida, quiçá também pensando na contemporaneidade.

\section{REFERÊNCIAS}

1. BEISIEGEL, Celso de Rui. Política e educação popular: a teoria e a prática de Paulo Freire no Brasil. São Paulo: Ática, 1982.

2. BEISIEGEL, Celso de Rui. Estado e educação popular: um estudo sobre a educação de adultos. São Paulo: Pioneira, 1974.

3. BRANDÃO, Carlos Rodrigues. O que é método Paulo Freire. 17. ed. São Paulo: Brasiliense, 1991.

4. CHARTIER, Roger. A história ou a leitura do tempo. Belo Horizonte: Autêntica Editora, 2009.

5. CORREIO DO POVO. Porto Alegre, ano 68, n. 224, p. 10, 28 jul.1963.

6. CORREIO DO POVO. Porto Alegre, ano 69, n. 73, p.12, 27 dez. 1963.

7. CORREIO DO POVO. Porto Alegre, ano 69, n. 89, p. 4, 16 jan. 1964.

8. FERRARO, Alceu Ravanello. História inacabada do analfabetismo no Brasil. São Paulo: Cortez, 2009.

9. FICO, Carlos. Além do Golpe. Versões e controvérsias sobre 1964 e a Ditadura Militar. Rio de Janeiro: Record, 2004.

10. FREIRE, Ana Maria Araújo. Notas de Ana Maria Araújo Freire. In: FREIRE: Paulo. Cartas a Cristina: Reflexões sobre minha vida e minha práxis. 4. ed. São Paulo: Paz e Terra, 2015.

11. FREIRE, Paulo. Educação como prática da liberdade. 24. ed. Rio de Janeiro: Paz e Terra Ltda, $2000 a$

12. FREIRE, Paulo. Posfácio: Depoimento de um grande amigo. In: FIORI, Ernani Maria. Textos escolhidos. Porto Alegre: L\&PM, 1992. 2 v.

13. FREIRE, Paulo. Extensão ou comunicação? 7.ed. Rio de Janeiro: Paz e Terra, 1983. 
FREIRE, Paulo. Cartas a Cristina: Reflexões sobre minha vida e minha práxis. 2. ed. São Paulo: Paz e Terra, 2015.

FREIRE, Paulo. "Educação e atualidade brasileira". In: ROMÃO, José Eustáquio (org.). Educação e atualidade brasileira. 3. ed. São Paulo: Cortez; Instituto Paulo Freire, 2003.

FREITAS, Marcos Cezar de; BICCAS, Maurilane de Souza. História social da educação no Brasil (1926-1996). São Paulo: Cortez, 2009. Educação, São Paulo, n. 14, p.108-130, 2000. Disponível em: www.scielo.br/pdf/rbedu/n14/n14a07. Acesso em: 26 nov. 2018.

JORNAL DO DIA. Porto Alegre, ano XVII, n. 4526, p. 6, 26 nov. 1963. Disponível em: http://memoria.bn.br/DocReader/docreader.aspx?bib=098230\&pasta=ano\%20196\&pesq=umespa. Acesso em: 05 jun. 2018.

SEMANÁRIO. Rio de Janeiro, ano VIII, n. 371, p. 7, 6-9 fev. 1964. Disponível em: http://memoria.bn.br/DocReader/docreader.aspx?bib=149322\&pasta=ano\%20196\&pesq=igreja $\% 20$ e\%20os\%20americanos\%20ap\%C3\%B3iam\%20m\%C3\%A9todo. Acesso em: 03 jun. 2019. PAIVA, Vanilda Pereira. Educação popular e educação de adultos. 5.ed. São Paulo: Loyola, 1987. QUADROS, Claudemir de. As Brizoletas cobrindo o Rio Grande: a educação pública no Rio Grande do Sul durante o governo de Leonel Brizola (1959-1963). Santa Maria, RS: Editora UFSM, 2003. ROSAS, Paulo. Recife: cultura e participação (1950-64). In: ROMÃO, José Eustáquio (org.). Educação e atualidade brasileira. 3. ed. São Paulo: Cortez; Instituto Paulo Freire, 2003.

ÚLTIMA HORA. Rio de Janeiro, ano XIII, n. 1255, p. 4, 11 mar. 1964. Disponível em: http://memoria.bn.br/DocReader/docreader.aspx?bib=386030\&pasta=ano\%20196\&pesq=. Acesso em: 04 jun. 2019.

ÚLTIMA HORA. Rio de Janeiro, ano XIII, n. 1278, capa, 16 abr. 1964. Disponível em: http://memoria.bn.br/DocReader/docreader.aspx?bib=386030\&pasta=ano\%20196\&pesq=. Acesso em: 04 jun. 2019.

WEFFORT, Francisco C. Educação e Política: Reflexões sociológicas sobre uma pedagogia da liberdade. In: FREIRE, Paulo. Educação como prática da liberdade. Rio de Janeiro: Paz e Terra Ltda, 2000. 


\section{Mariana Parise Brandalise Dalsotto}

Doutoranda no Programa de Pós-Graduação em Educação da Universidade de Caxias do Sul (UCS), vinculada à linha de pesquisa História e Filosofia da Educação. Bolsista CAPES. Mestre em educação pela Universidade de Caxias do Sul e Graduada em Pedagogia (Licenciatura) pela mesma universidade.

\section{Terciane Ângela Luchese}

Possui graduação em Licenciatura Plena em História pela Universidade de Caxias do Sul, mestrado em História pela Pontifícia Universidade Católica do Rio Grande do Sul e doutorado em Educação - Linha de Pesquisa Currículo, Cultura e Sociedade, UNISINOS. É professora da Universidade de Caxias do Sul, atua na graduação e nos Programas de Pós-Graduação em História e no de Pós-Graduação em Educação - Curso de Mestrado e Doutorado, tendo sido coordenadora do PPGEdu/UCS.

\section{Como citar este documento:}

DALSOTTO, Mariana Parise Brandalise; LUCHESE, Terciane Ângela. Círculos de cultura: história de uma prática de educação popular (déc. De 1950 - 1960). Reflexão e Ação, Santa Cruz do Sul, v. 27 , n. 3, p. 72-90, out. 2019. ISSN 1982-9949. Disponível em: $<$ https://online.unisc.br/seer/index.php/reflex/article/view/13648>. Acesso em:__. doi:https://doi.org/10.17058/rea.v27i3.13648. 